\title{
Entry, Descent, and Landing Performance of the Mars Phoenix Lander
}

\author{
Prasun N. Desai ${ }^{*}$, Jill L. Prince ${ }^{\dagger}$, Eric M. Queen ${ }^{\ddagger}$, and Juan R. Cruz ${ }^{\S}$ \\ NASA Langley Research Center, Hampton, VA, 23681 \\ Myron R. Grover ${ }^{* *}$ \\ Jet Propulsion Laboratory, Pasadena, CA 91109
}

\begin{abstract}
On May 25, 2008, the Mars Phoenix Lander successfully landed on the northern arctic plains of Mars. An overview of a preliminary reconstruction analysis performed on each entry, descent, and landing phase to assess the performance of Phoenix as it descended is presented and a comparison to pre-entry predictions is provided. The landing occurred $21 \mathrm{~km}$ further downrange than the predicted landing location. Analysis of the flight data revealed that the primary cause of Phoenix's downrange landing was a higher trim total angle of attack during the hypersonic phase of the entry, which resulted in Phoenix flying a slightly lifting trajectory. The cause of this higher trim attitude is not known at this time. Parachute deployment was $6.4 \mathrm{~s}$ later than prediction. This later deployment time was within the variations expected and is consistent with a lifting trajectory. The parachute deployment and inflation process occurred as expected with no anomalies identified. The subsequent parachute descent and powered terminal landing also behaved as expected. A preliminary reconstruction of the landing day atmospheric density profile was found to be lower than the best apriori prediction, ranging from a few percent less to a maximum of $8 \%$. A comparison of the flight reconstructed trajectory parameters shows that the actual Phoenix entry, descent, and landing was close to pre-entry predictions. This reconstruction investigation is currently ongoing and the results to date are in the process of being refined.
\end{abstract}

$\begin{array}{ll}\mathrm{a} & =\text { acceleration } \\ \mathrm{C}_{\mathrm{D}} & =\text { drag coefficient } \\ \mathrm{E} & =\text { atmospheric entry time } \\ \mathrm{EDL} & =\text { entry, descent, and landing } \\ \mathrm{F} & =\text { force } \\ \mathrm{IMU} & =\text { Inertial Measurement Unit } \\ \mathrm{L} & =\text { landing time } \\ \mathrm{m} & =\text { mass } \\ \mathrm{M} & =\text { Mach number } \\ \text { MCS } & =\text { Mars Climate Sounder } \\ \text { MOLA } & =\text { Mars Orbiter Laser Altimeter }\end{array}$

Nomenclature
\[ \begin{array}{ll}\text { MRO } & =\text { Mars Reconnaissance Orbiter } \\ \mathrm{q} & =\text { dynamic pressure } \\ \mathrm{r} & =\text { radius from center of Mars } \\ \mathrm{RSS} & =\text { root sum square } \\ \mathrm{S} & =\text { reference area } \\ \mathrm{V} & =\text { velocity } \\ \mathrm{V}_{\mathrm{v}} & =\text { vertical velocity } \\ \mathrm{V}_{\mathrm{v}} & =\text { vertical velocity } \\ \gamma & =\text { inertial flight-path angle } \\ \rho & =\text { atmospheric density }\end{array} \]

\footnotetext{
*Senior Aerospace Engineer, Atmospheric Flight \& Entry Systems Branch, MS 489, prasun.n.desai@nasa.gov, AIAA Associate Fellow.

${ }^{\dagger}$ Aerospace Engineer, Atmospheric Flight \& Entry Systems Branch, MS 489, jill.1.prince@nasa.gov, AIAA Member.

\$Senior Aerospace Engineer, Atmospheric Flight \& Entry Systems Branch, MS 489, eric.m.queen@nasa.gov, AIAA Member.

${ }^{\S}$ Senior Aerospace Engineer, Atmospheric Flight \& Entry Systems Branch, MS 489, juan.r.cruz@nasa.gov, AIAA Member.

${ }^{* *}$ Senior Aerospace Engineer, EDL Systems Advanced Technologies Group, 4800 Oak Grover Drive, MS 264-623, myron.r.grover@jpl.nasa.gov, AIAA Member.
} 


\section{Introduction}

$\mathrm{T}$ HE Mars Phoenix Lander successfully landed on Mars on May 25, 2008 in the northern arctic plains in Vastitas Borealis. Its science objective is to search for habitable regions on Mars, continuing the search for the evidence of liquid water. Reference 1 provides an overview of the mission. Upon Mars arrival, the capsule containing the lander was separated from the cruise stage $7 \mathrm{~min}$ prior to entry interface, initiating the entry, descent and landing (EDL) phase of the mission. The lander decelerated with the aid of an aeroshell, a supersonic parachute, and retrorockets prior to landing safely on the surface. The Phoenix EDL phases and the nominal sequence of events for traversing through the atmosphere for the soft landing are illustrated in Figure 1. The Phoenix entry was divided into four phases: 1) Entry Preparation - from cruise-stage separation to entry interface, 2) Hypersonic - from entry interface to parachute deployment, 3) Parachute - from parachute deployment to lander separation, and 4) Terminal Descent - from lander separation to touchdown. Reference 2 provides an overview of the evolution of this Phoenix EDL architecture.

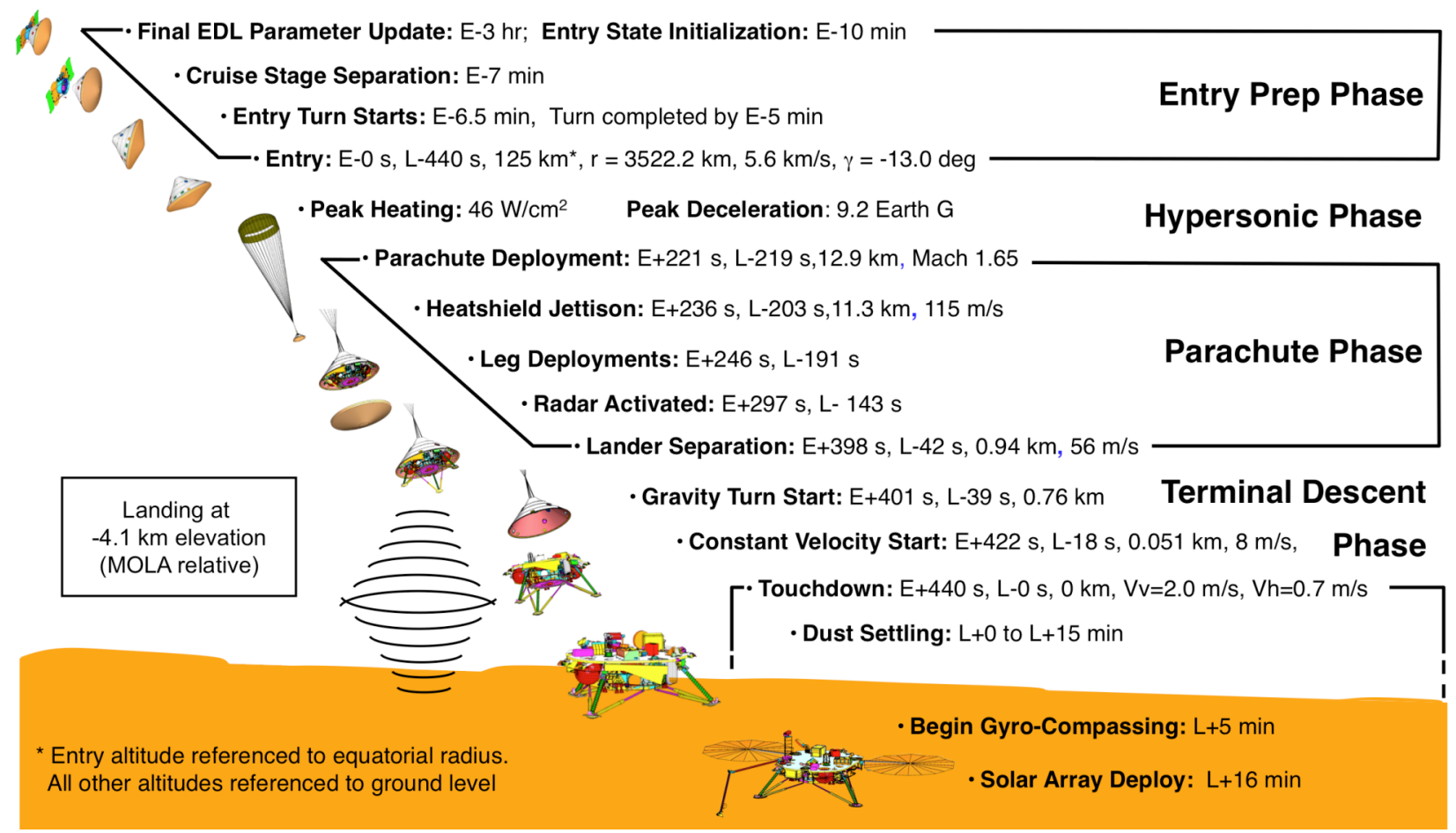

Figure 1. Phoenix EDL sequence of events.

The Mars approach maneuvers and targeting procedures were nominal and placed the capsule on the desired flight path required for a successful entry.,4 The nominal design values at entry interface (radius of $3522.2 \mathrm{~km}$ corresponding to a $125 \mathrm{~km}$ radial altitude) for the inertial entry velocity and inertial flight-path angle for Phoenix were $5.6 \mathrm{~km} / \mathrm{s}$ and $-13.0^{\circ}$, respectively. At entry (E) minus $6.5 \mathrm{~min}$, the 3-axis controlled capsule performed a turn-toentry maneuver to attain the desired nominal zero degree angle of attack attitude at entry interface (E- 0 s). Early in the entry after sensing 0.03 Earth $\mathrm{G}$, the control system deadbands were widened sufficiently to essentially eliminate thruster firings due to concerns of a control system instability (i.e., potential reversal) arising from an interaction between the aerodynamic flowfield around the capsule and the reaction control system. Reference 5 provides a detailed description of this issue. The rationale for the control system deadband settings during the hypersonic phase is provided is Ref. 2. As such, during the hypersonic phase, the capsule relied on its inherent aerodynamic stability to traverse all the flight regimes (rarefied, transitional, hypersonic, supersonic) until parachute deployment. ${ }^{6}$ Although Phoenix was designed for a 3-axis controlled entry, it was actually configured to enter uncontrolled. ${ }^{2}$ Consequently, Phoenix became the first ballistic non-spinning spacecraft without hypersonic thruster control to land on Mars.

During the hypersonic phase, the predicted nominal peak deceleration was estimated to be 9.3 Earth G. Parachute deployment was triggered on accelerometer measurements from an Inertial Measurement Unit (IMU) and was nominally targeted for an acceleration value of $7.42 \mathrm{~m} / \mathrm{s}^{2}(0.756$ Earth G), which corresponded to a dynamic pressure of $490 \mathrm{~N} / \mathrm{m}^{2}$ and a Mach number of 1.65 . Heatshield separation was timed to occur $15 \mathrm{~s}$ after parachute de- 
ployment. Lander leg deployment was timed to occur $10 \mathrm{~s}$ after heatshield separation. The radar was timed to be activated $15 \mathrm{~s}$ after lander leg deployment. Lander separation from the backshell/parachute system was based on radar measurements and was nominally to occur at an altitude of $940 \mathrm{~m}$ above ground level (AGL). Throttle up and start of the gravity turn was timed to initiate $3 \mathrm{~s}$ after lander separation, which transitions into a constant velocity phase at a vertical velocity of $8 \mathrm{~m} / \mathrm{s}$ leading to touchdown.

This paper provides an overview of the preliminary reconstruction analysis performed to date for the Phoenix entry to ascertain how well the actual EDL events compared to the nominal pre-entry sequence of events illustrated in Fig. 1. Accelerometer and gyro data from the IMU and radar data were analyzed to determine the actual event times and the as flown trajectory. Each entry phase was examined to assess the performance of Phoenix as it descended to quantify how well the pre-entry predictions compared to the actual flight. Lastly, a preliminary comparison of the atmospheric density encountered during the entry to the pre-entry profile is presented.

\section{Landing Location}

The navigation accuracy obtained for Phoenix yielded extremely small state errors upon Mars arrival. ${ }^{4}$ The final orbit determination solution produced the desired nominal inertial entry flight-path angle of $-13.0^{\circ}$ with a $\pm 3-\sigma$ error of $\pm 0.007^{\circ}$, which was well within the $\pm 0.15^{\circ}$ requirement. The corresponding inertial velocity at entry interface was $5.6 \mathrm{~km} / \mathrm{s}$ having a $\pm 3-\sigma$ error of $\pm 0.44 \mathrm{~m} / \mathrm{s}$.

Using this final orbit determination solution, a final pre-entry predicted landing location (blue circle) was calculated that was approximately $17 \mathrm{~km}$ northnorthwest from the desired target of $68.151^{\circ}$ North Latitude and $233.975^{\circ}$ East Longitude (black x) as shown in Fig. 2. Note, the Phoenix flight-track went from northwest to southeast. The final pre-entry predicted landing location was uptrack of the target, because TCM-6 was not performed to move it closer. The risks associated with performing a TCM so close to entry more than outweighed the potential marginal gain from a landing closer to the target, since all EDL and landing site requirements were already satisfied. ${ }^{7,8}$ The corresponding final pre-entry predicted $99 \%$ footprint ellipse was estimated to be $55.1 \mathrm{~km}$ by $19.2 \mathrm{~km}$ having an approach azimuth of $108^{\circ}$ (positive from North), which was well within the design requirement of $110 \mathrm{~km}$ by $20 \mathrm{~km}$. The actual Phoenix landing location (red diamond) of $68.219^{\circ}$ North Latitude and $234.248^{\circ}$ East Longitude was $4.1 \mathrm{~km}$ downtrack and $5.9 \mathrm{~km}$ crosstrack from the target, and $21 \mathrm{~km}$ downtrack and $5.3 \mathrm{~km}$ crosstrack from the final pre-entry prediction as shown in Fig 2. The actual landing loca-

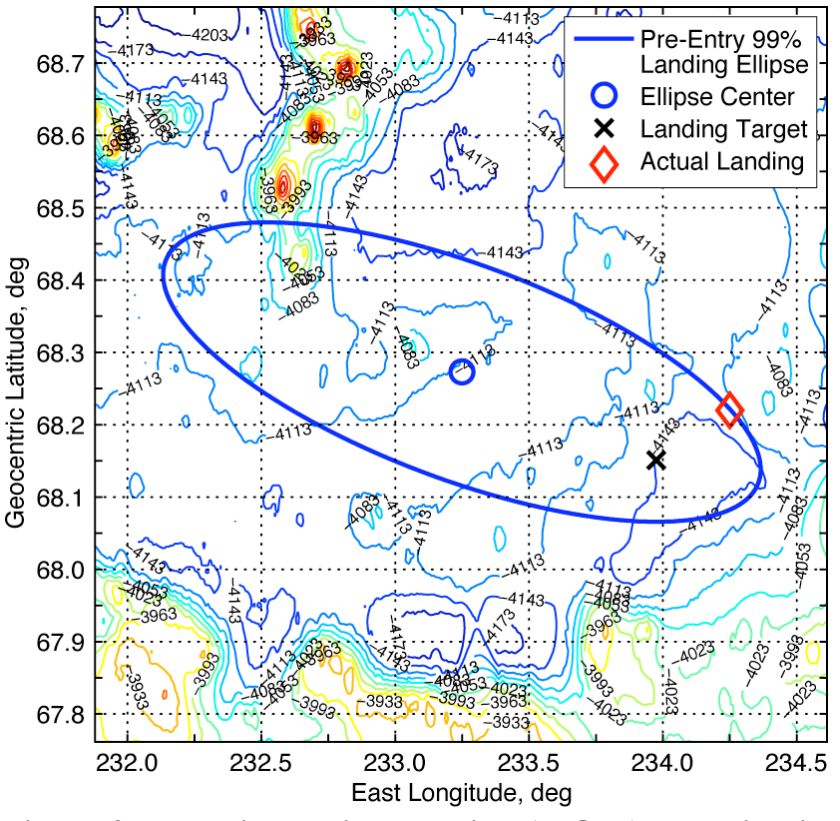

Figure 2. Phoenix landing location (MOLA elevation in meters).

tion was just inside the final pre-entry predicted $99 \%$

footprint ellipse, but again was well inside the design requirement of $110 \mathrm{~km}$ by $20 \mathrm{~km}$. Also depicted in Fig. 2 is the landing site elevation relative to the Mars Orbiter Laser Altimeter (MOLA) reference. The Phoenix landing region was approximately $-4100 \mathrm{~m}$ below the MOLA reference. The reason for Phoenix traveling further downtrack and crosstrack (towards the northeast) from the predicted landing location is discussed in the next section. However, the arrival navigation state can be ruled out as a possible cause, since the desired arrival state was achieved with very high accuracy as previously cited.

\section{Hypersonic Phase}

For the Phoenix entry, nearly the entire deceleration occurs in the hypersonic phase. As such, its performance during this phase will dictate the landing location to a very large extent. Analysis of the accelerometer data revealed that Phoenix experienced a peak deceleration of 8.5 Earth G occurring at $123 \mathrm{~s}$ after entry interface. In comparison, the pre-entry nominal peak deceleration predicted was 9.3 Earth $\mathrm{G}$ occurring at $121 \mathrm{~s}$ after entry interface. Since the actual peak deceleration was lower and later than the pre-entry nominal prediction, this situation was an early indication that Phoenix's actual flight was shallower than the prediction, and thus, would lead to a landing further down- 
track. This shallower flight is observed in Fig. 3, which shows Phoenix's reconstructed relative flightpath angle during the hypersonic phase. The flightpath angle starts to deviate from the pre-entry prediction as peak deceleration approaches and remains shallower for the duration of the hypersonic phase.

The reason for this shallower flight was revealed by Phoenix's reconstructed hypersonic attitude history. Figure 4 shows the reconstructed total angle of attack of Phoenix from entry interface to just prior to parachute deployment. As seen, Phoenix trimmed at a larger total angle of attack than the pre-entry nominal prediction. Early in the entry (from 0 to $75 \mathrm{~s}$ ), the attitude was very similar to the pre-entry nominal prediction. However, as the descent continued, Phoenix trimmed at a larger total angle of attack. From $75 \mathrm{~s}$ to $125 \mathrm{~s}$, the trim total angle of attack averaged approximately $3^{\circ}$, while the estimate for the pre-entry nominal prediction was roughly $0.5^{\circ}$. Note, although, Phoenix was a ballistic entry, any slight radial center of mass offset will result in a small trim angle of attack prediction as seen in Fig. 4. From 125 $\mathrm{s}$ to $190 \mathrm{~s}$, the trim total angle of attack was approximately $0.9^{\circ}$ compared to the pre-entry nominal prediction of $0.25^{\circ}$. The exact reason for Phoenix's larger trim total angle of attack is not know at this time, and is currently under investigation. However, a number of sources that could produce this higher trim angle are: 1) a larger radial center of gravity offset than estimated, 2) a mis-prediction of the aerodynamics of the capsule, 3) a deformation of the capsule forebody, or 4) asymmetries in the aeroshell forebody.

The two attitude peaks occurring at approximately $77 \mathrm{~s}$ and $123 \mathrm{~s}$ that increase the total angle of attack to approximately $3^{\circ}$ are known aerodynamic static instabilities which were predicted and expected for a blunt body capsule such as Phoenix. Reference 6 provides an in-depth description of the Phoenix capsule aerodynamics and an explanation of the cause of these two static instabilities. As the descent continue into the supersonic regime (Mach 3 and below) approaching parachute deployment, the growth in the attitude observed from $190 \mathrm{~s}$ to $227 \mathrm{~s}$ was also predicted and expected, and arises from a supersonic dynamic instability phenomena that is present in blunt bodies. ${ }^{6}$ The pre-entry nominal prediction shows this attitude growth increasing from $0.25^{\circ}$ to $2.3^{\circ}$. The actual Phoenix reconstructed attitude is observed to grow much higher from $0.9^{\circ}$ to $4.75^{\circ}$ just prior to parachute deployment. Note, however, Phoenix's higher trim total angle of attack and larger attitude growth approaching parachute deployment were within the dispersions characterized through a Monte Carlo analysis as well as the design requirements, and are presented later in Section VII.

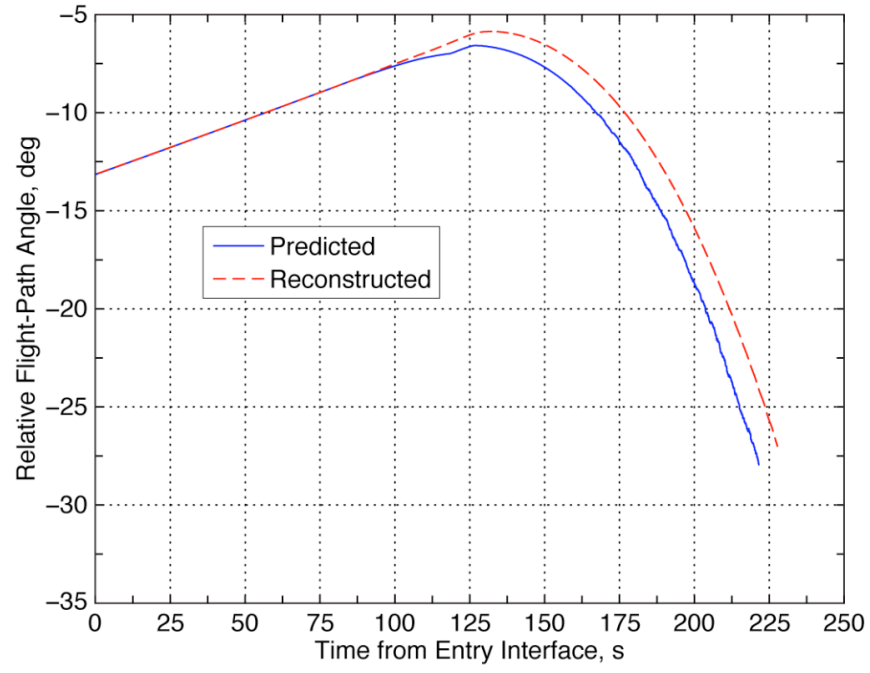

Figure 3. Reconstructed relative flight-path angle.

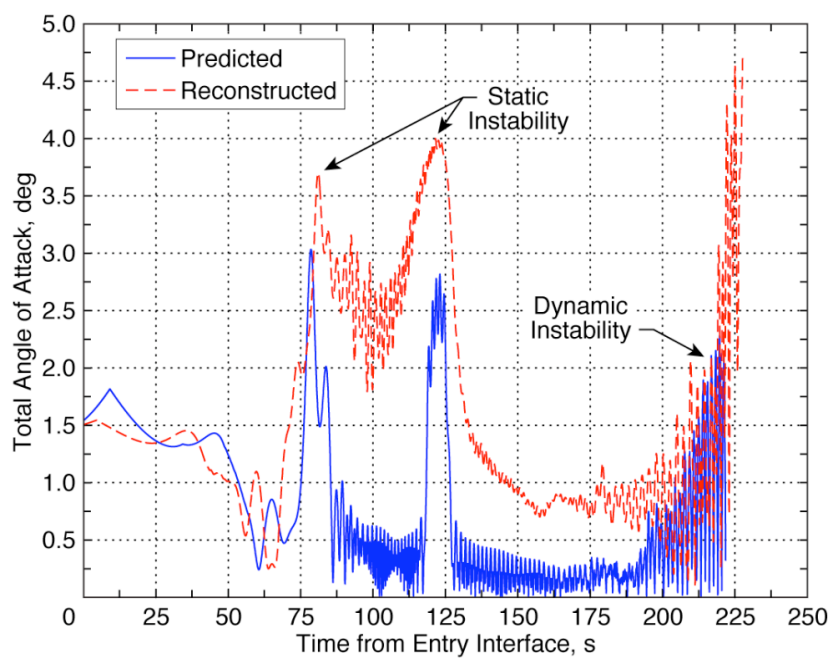

Figure 4. Reconstructed total angle of attack.

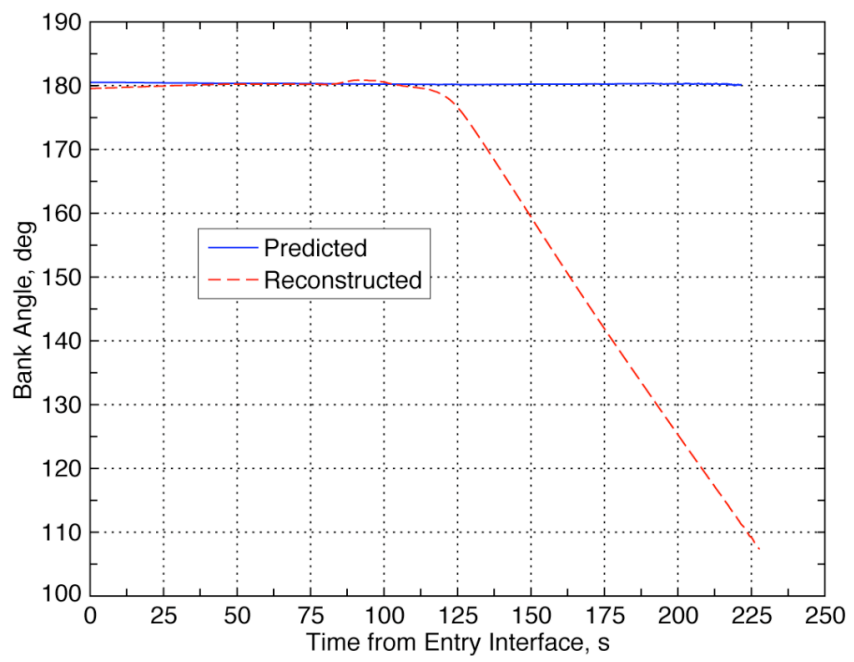

Figure 5. Reconstructed bank angle. 
Prior to entry, Phoenix was set to a lift-up orientation (Bank angle of $180^{\circ}$ ). The reconstructed Bank angle for Phoenix during hypersonic flight is shown in Fig. 5. As seen, early in the entry, the Bank angle remains at the pre-entry setting of $180^{\circ}$ (pure lift-up). Approaching peak deceleration (time of $\sim 115 \mathrm{~s}$ ), however, the Bank angle begins to decrease at a constant Bank rate of approximately $-0.7 \mathrm{deg} / \mathrm{s}$ to $107^{\circ}$ just prior to parachute deployment. During this time, the capsule rotated an increasing portion of its lift vector out of the pure lift-up plane (Bank angle of $180^{\circ}$ ) and into a side-lift orientation (Bank angle of $107^{\circ}$ ), thereby exchanging some downtrack movement for some crosstrack movement. Consequently, Phoenix's larger trim total angle of attack produced a lifting trajectory that resulted in the landing location being $21 \mathrm{~km}$ further downtrack from the pre-entry landing prediction. This lifting trajectory is also consistent with producing the reconstructed shallower flight-path angle (shown in Fig. 3), as well as the later time and lower peak deceleration experienced during the entry. The reconstructed Bank angle history explains the crosstack landing location of $5.3 \mathrm{~km}$ towards the northeast. The decreasing Bank angle during the entry from $180^{\circ}$ to $107^{\circ}$ indicated a slow rotation of the lift vector from pure lift-up (i.e., downtrack direction) to a portion into the crosstrack direction that is consistent with a movement towards the northeast.

The measured capsule body rates about the roll, pitch, and yaw axes during hypersonic flight are shown in Figs. 6-8. The roll rate remains near zero until peak deceleration when a slow increase is observed before settling to a constant value of approximately $-0.7 \mathrm{deg} / \mathrm{s}$ after $125 \mathrm{~s}$. The pitch and yaw rates are comparable to the pre-entry nominal prediction through peak deceleration. The comparison is less favorable during the supersonic dynamic instability region; although, the larger difference observed is consistent with the larger reconstructed attitude growth seen in Fig. 4. The frequency of the body rates can be used to assess the aerodynamics of the capsule, specifically its static stability (i.e., the slopes of the pitching moment verses angle of attack and yawing moment verses side-slip curves). Due to the fairly good comparison of the frequency and phase of the body pitch and yaw rates to the preentry nominal prediction is a preliminary indication that the aerodynamics generated for Phoenix $^{6}$ (static and dynamic coefficients) captured its flight behavior reasonably well. A detailed aerodynamic reconstruction is currently underway.

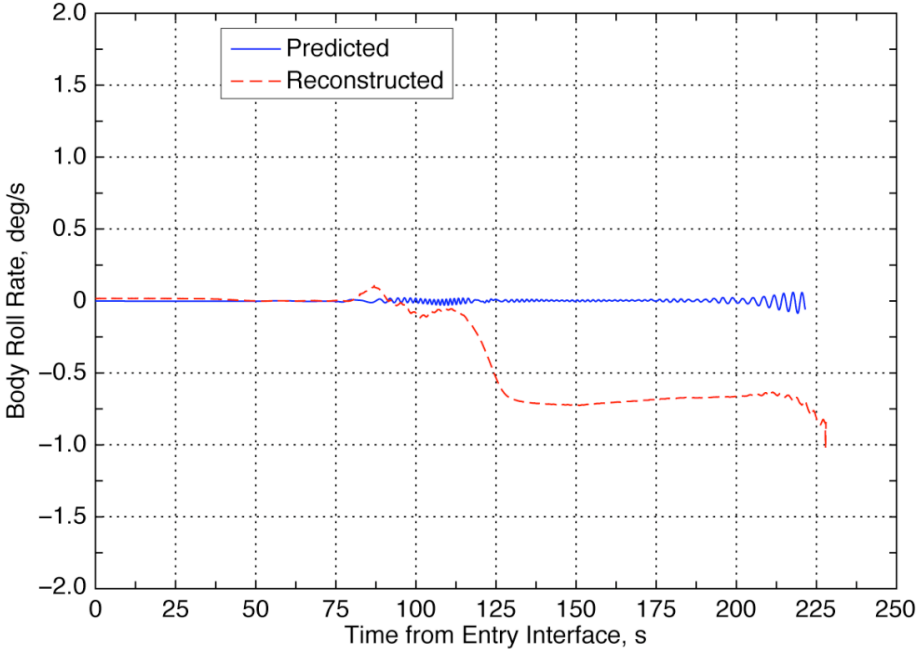

Figure 6. Reconstructed body roll rate.

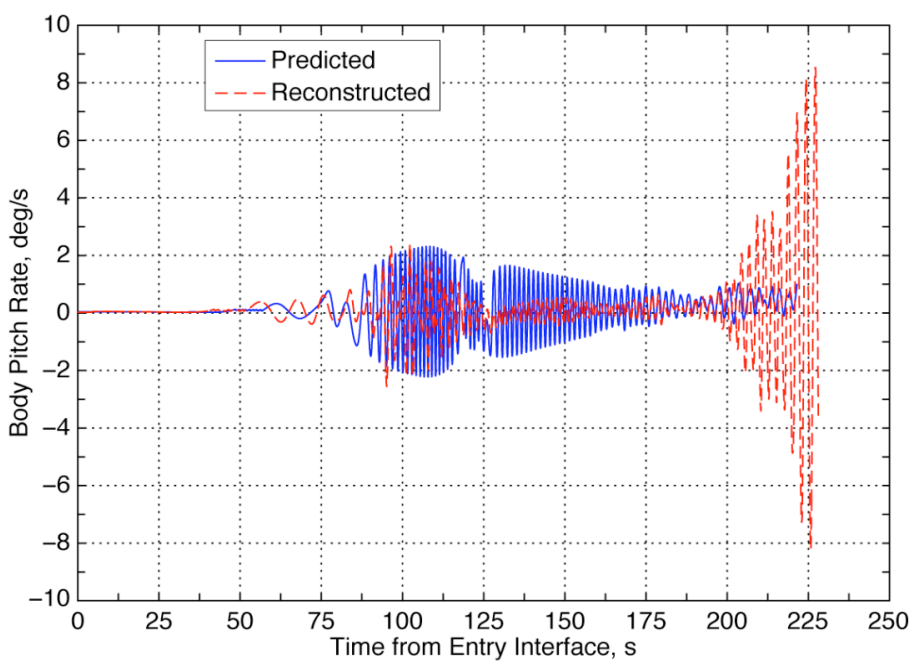

Figure 7. Reconstructed body pitch rate.

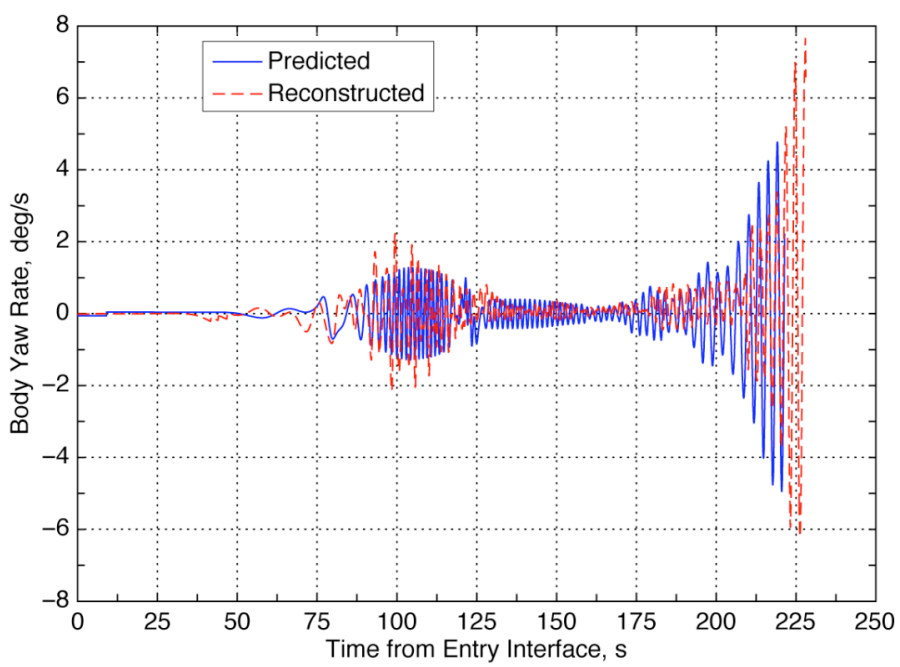

Figure 8. Reconstructed body yaw rate.

American Institute of Aeronautics and Astronautics 092407 
As mentioned previously, Phoenix was designed for a 3-axis attitude and rate damped controlled entry, but it was actually configured to enter uncontrolled due to the widening of the entry control system deadband settings, which essentially eliminated any thruster firings. ${ }^{2}$ As previously stated, this configuration change was due to concerns of a control system instability (i.e., potential reversal) arising from an interaction between the aerodynamic flowfield around the capsule and the plumes from thruster firings of the reaction control system. ${ }^{5}$ In the supersonic regime, where the thrusters were most likely to be utilized due to the aerodynamic dynamic instability that would produce large attitude and rate growth, the control system deadbands were widened as follows: pitch and yaw attitude deadbands were widened from $5^{\circ}$ to $15^{\circ}$; roll attitude deadband was widened from $1.7^{\circ}$ to infinity (i.e., no limit); pitch rate deadbands widened from $0.5 \mathrm{deg} / \mathrm{s}$ to $20 \mathrm{deg} / \mathrm{s}$; yaw rate deadbands widened from $3 \mathrm{deg} / \mathrm{s}$ to $20 \mathrm{deg} / \mathrm{s}$; and roll rate deadband widened from $0.03 \mathrm{deg} / \mathrm{s}$ to $20 \mathrm{deg} / \mathrm{s}$;. As inidicated in Figs. 6-8, the rates that Phoenix experienced during its entry would have triggered a large number of thruster firings in all three axes, if the deadbands were not widened, increasing the possibility of a control system instability. However, entering with the widened control system deadband configuration, telemetry data indicated that there were no thruster firings during the entry. As a result, Phoenix's predicted inherent aerodynamic stability was sufficient to traverse the entire hypersonic phase of the entry. Overall, the hypersonic phase went as expected with no real anomalies identified. Although, Phoenix trimmed at a higher total angle of attack than predicted, it was still within the variations expected. However, an investigation is underway to try to determine the cause.

\section{Parachute Phase}

\section{A. Parachute Deployment}

A preliminary reconstruction of the Phoenix parachute deployment, inflation and opening loads was performed using the accelerometer measurements from the IMU. Analysis of the flight data indicated that mortar fire occurred $227.84 \mathrm{~s}$ after entry interface triggering parachute deployment. This mortar fire event is clearly seen in Fig. 9, which shows the measured axial acceleration verses time from entry interface. The parachute deployment time was $6.4 \mathrm{~s}$ later than the pre-entry predicted nominal deployment time of $221.44 \mathrm{~s}$ after entry interface. This later deployment time is consistent with the lifting shallower flight trajectory flown by Phoenix.

The acceleration value just prior to mortar firing was $7.39 \mathrm{~m} / \mathrm{s}^{2}(0.753$ Earth $\mathrm{G})$, which was very close to the deployment trigger setting of $7.42 \mathrm{~m} / \mathrm{s}^{2}$ (0.756 Earth G). The corresponding reconstructed dynamic pressure and Mach number at parachute deployment were estimated to be $488.9 \mathrm{~N} / \mathrm{m}^{2}$ and 1.7 , respectively, which were very close to the target values of $490 \mathrm{~N} / \mathrm{m}^{2}$ and Mach 1.65. The instantaneous total angle of attack at the parachute deployment time of $227.84 \mathrm{~s}$ was reconstructed to be $4.73^{\circ}$, which was well with the design reqirement of $10^{\circ}$. It appears that parachute deployment was actually triggered at the peak of the attitude oscillation observed in Fig. 4, as opposed to a possible lower value of the cycle, which ranged between $0.25^{\circ}$ and $4.75^{\circ}$. The reconstructed height at parachute deployment was calculated to be $13.3 \mathrm{~km}$ (AGL), which was slightly higher compared to $12.9 \mathrm{~km}$ (AGL) predicted from the preentry nominal. This higher parachute deployment height is again consistent with the lifting trajectory that Phoenix experienced on landing day.

The times for line stretch and first peak load from mortar fire were $0.75 \mathrm{~s}$ and $1.115 \mathrm{~s}$, respectively. These times were slightly shorter than the pre-entry estimates

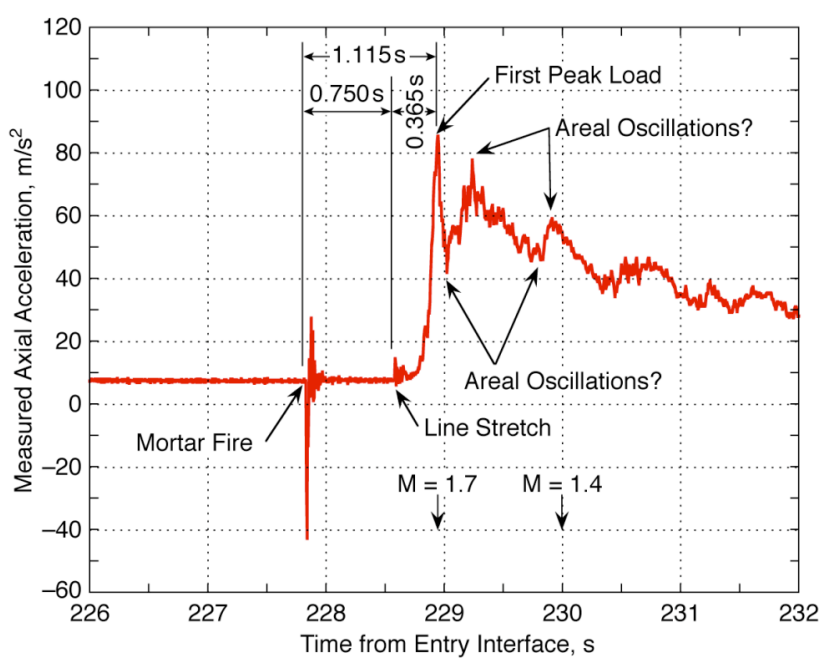

Figure 9. Measured axial acceleration during parachute deployment.

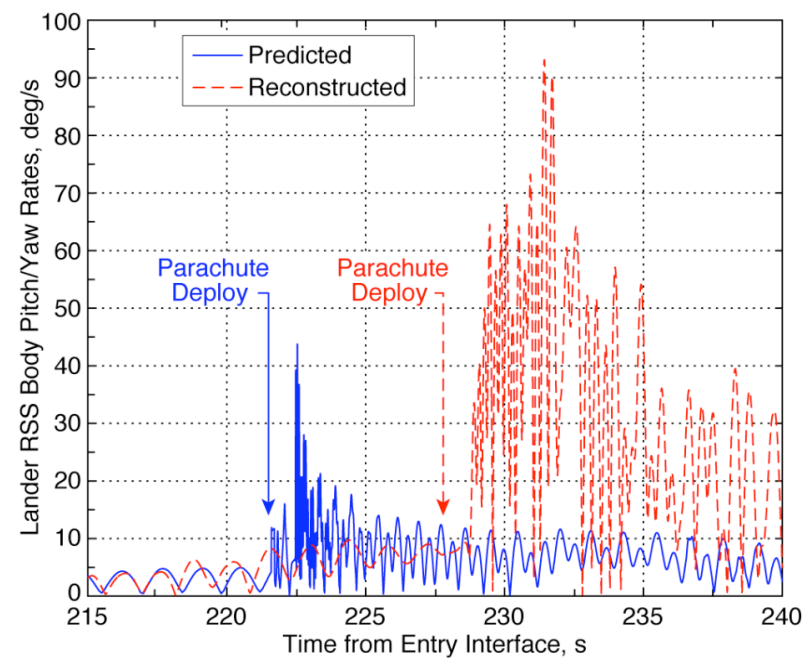

Figure 10. Lander RSS body pitch and yaw rates during parachute deployment.

6

American Institute of Aeronautics and Astronautics 092407 
of $0.803 \mathrm{~s}$ and $1.234 \mathrm{~s}$, respectively. The peak load estimated from the flight data was 44,800 N, which was well below the flight load requirement of 59,600 N. After peak load, the flight data indicates possible areal oscillations of the parachute (i.e., parachute could be breathing - opening and closing, a phenomena associated with disk-gap-band parachutes operating at supersonic conditions) before remaining fully open after $230 \mathrm{~s}$. Below Mach 1.4, areal oscillations are unlikely.

Figure 10 shows a comparison of the root sum square (RSS) of the capsule body pitch and yaw rates hanging under the parachute between the pre-entry nominal prediction and the measured data. Initially, high rates are present as expected due to the parachute deployment process, which then damp down very quickly thereafter. As seen, the peak measured RSS rates (approx. $90 \mathrm{deg} / \mathrm{s}$ ) are approximately twice as large as the pre-entry predicted nominal (approx. $45 \mathrm{deg} / \mathrm{s}$ ). This result is a consequence of the larger total angle of attack of $4.75^{\circ}$ at parachute deployment compared to the much lower value for the pre-entry prediction of $1.8^{\circ}$. However, these high reconstructed rates in Fig. 10 are well within the dispersions characterized through a Monte Carlo analysis, and will be presented later in Section VII. Overall, the parachute deployment and inflation process went as expected with no anomalies identified.

\section{B. Parachute Descent}

A reconstruction of the lander descent history during the parachute phase (i.e., from parachute deployment to lander separation) is shown in Figs. 11-14. The reconstructed lander total angle of attack, pitch angle, RSS body pitch and yaw rates, and roll rate while hanging under the parachute are compared to the pre-entry nominal predication, which was calculated using a multi-body parachute/lander simulation. Reference 9 provides a detailed description of the development of this multi-body simulation that was utilized during the design phase in an effort to obtain realistic two-body dynamics of the Phoenix parachute/lander system. The parachute deployment and lander separation events from the reconstruction and the pre-entry nominal prediction are identified.

As seen in Figs. 11-14 and discussed in the previous subsection, the reconstructed parachute deployment time was $6.4 \mathrm{~s}$ later than the pre-entry nominal prediction. Similarly, the reconstructed time for lander separation was also later by $7.8 \mathrm{~s}(404.84 \mathrm{~s}$ verses a prediction of $397.04 \mathrm{~s}$ ). The multi-body simulation does reasonably predict the lander total angle of attack, pitch angle, and RSS rates in comparison to the reconstruction. The amplitude and frequency are very similar, although they are slightly out of phase (not unexpected do to the different parachute deployment times). The predicted and reconstructed lander total angle of attack (Fig. 11) varied roughly between $5^{\circ}$ and $25^{\circ}$. The mean total angle of attack in both the prediction and reconstruction is seen to increase slowing during the parachute descent starting from approximately $5^{\circ}$ after parachute deployment rising to approximately $12^{\circ}$ prior to lander separation. Figure 12 compares the lander pitch angle, where $-90^{\circ}$ points vertically down. After parachute deployment, approximately $60 \mathrm{~s}$ were required for the trajectory to turn near vertical. Thereafter, the lander oscillated about a pitch angle of $-80^{\circ}\left(10^{\circ}\right.$ from vertical $)$ under the parachute. The reason for this $10^{\circ}$ offset is be-

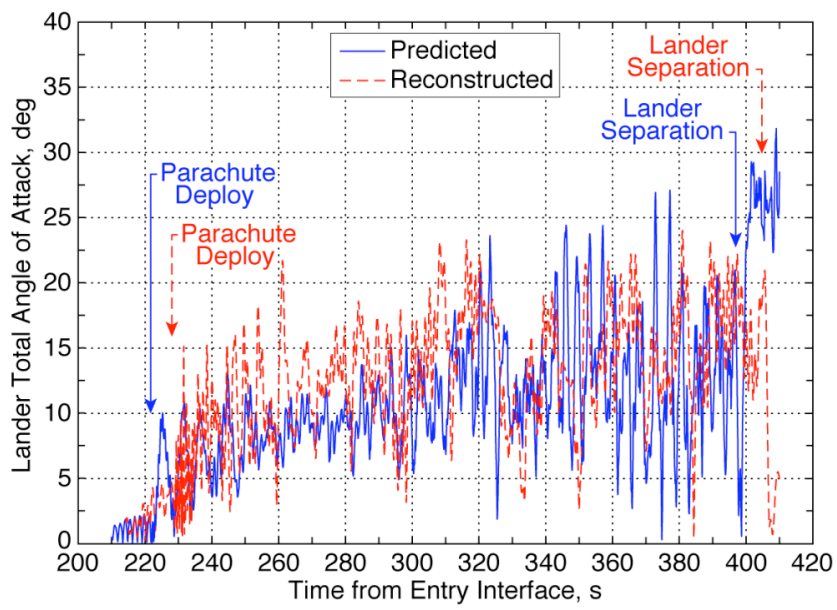

Figure 11. Lander total angle of attack during the parachute descent phase.

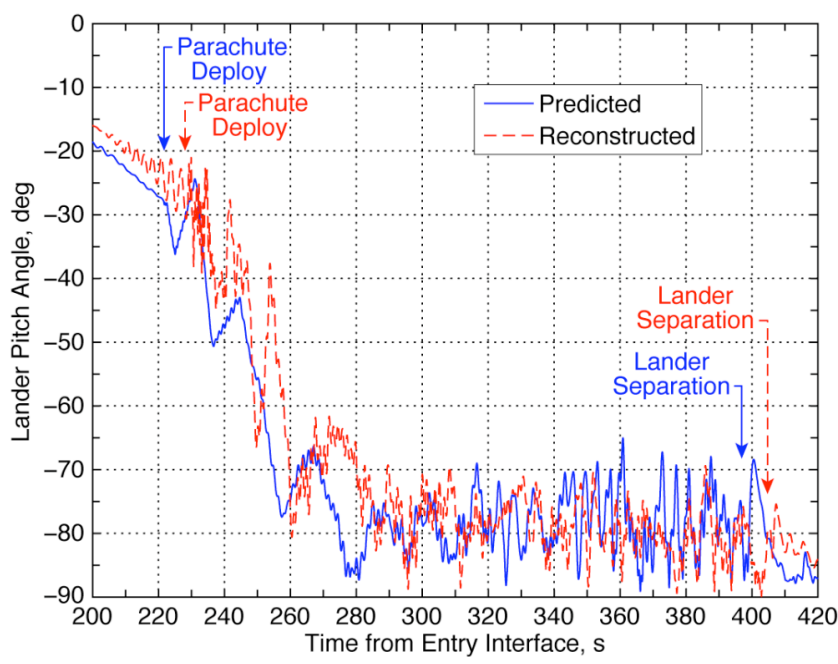

\section{Figure 12. Lander pitch angle during the parachute} descent phase.

cause the parachute trims at approx. $9^{\circ}$ as discussed in Ref. 9 . Since the aerodynamics of the parachute dominate the parachute/lander system, the parachute trim attitude dictates the trim attitude of the lander as well. 
The lander RSS body pitch/yaw rates and roll rates are shown in Figs. 13 and 14, respectively, during parachute descent. After peaking initially during the parachute deployment process (as discussed in the previous subsection), the RSS rates damp out very quickly as observed in Fig. 13. By the times of heatshield separation (15 s after parachute deployment) and lander leg deployment (10 s after heatshield separation), the RSS rates have decreased below $30 \mathrm{deg} / \mathrm{s}$ and remain so for the duration of the parachute descent phase. Figure 14 shows the roll rate history during parachute descent. The comparison between the prediction and reconstructed roll rate is not as good. A roll rate peaking at approximately $8 \mathrm{deg} / \mathrm{s}$ is observed in the reconstruction while descending on the parachute (resulting in the approx. 3.5 revolutions of the lander), while there is only a very small roll rate in the prediction. However, this reconstructed higher roll rate is within the dispersions characterized through a Monte Carlo analysis, and is presented later in Section VII.

In future analyses, an attempt will be undertaken to determine if the initial high rates experienced by Phoenix during parachute deployment can be reproduced by the multi-body simulation, if it was initialized with the same reconstructed deployment conditions (e.g., namely the higher parachute deployment total angle of attack). In addition, the larger roll rate observed in the reconstruction will be further studied to determine its cause. Overall, though, the parachute phase went as expected with no anomalies identified.

\section{Terminal Descent Phase}

A reconstruction of the lander descent during the terminal descent phase (i.e., from lander separation to touchdown) is presented in Figs. 15-18. The reconstructed and pre-entry nominal prediction lander pitch angle and trajectory profiles are shown in Figs. 15 and 16. Overall, the comparison is observed to be quite good. Shortly after separation $(927.4 \mathrm{~m}$ verses a prediction of $982.9 \mathrm{~m}$ ), the lander performed a tip-up maneuver (at approx. $800 \mathrm{~m}$ ) increasing its pitch angle to initiate the gravity turn descent to the surface. The reconstructed pitch angle $\left(-75^{\circ}\right)$ was slightly lower than the prediction $\left(-68^{\circ}\right)$. Also identified in the figure is the constant velocity phase just prior to touchdown, which began at $52.1 \mathrm{~m}$ in the reconstruction compared to $56.8 \mathrm{~m}$ in the prediction. The telemetry data indicated that the backshell avoidance maneuver $^{2}$, which would divert the lander further upwind to provide sufficient separation between it and the parachute in a low or no wind situation, was not employed.

The reconstructed and the predicted lander RSS body pitch and yaw rates are shown in Fig. 17. Again,

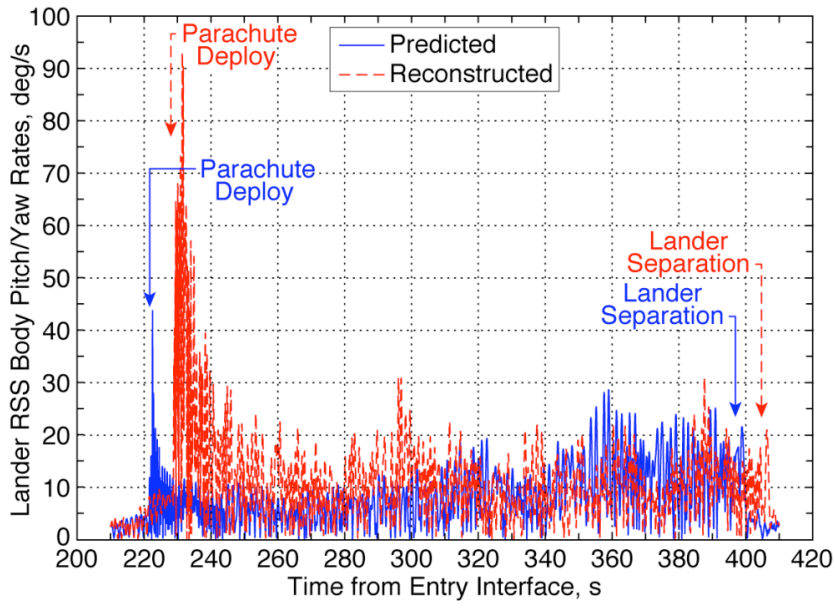

Figure 13. Lander RSS body pitch and yaw rates during the parachute descent phase.

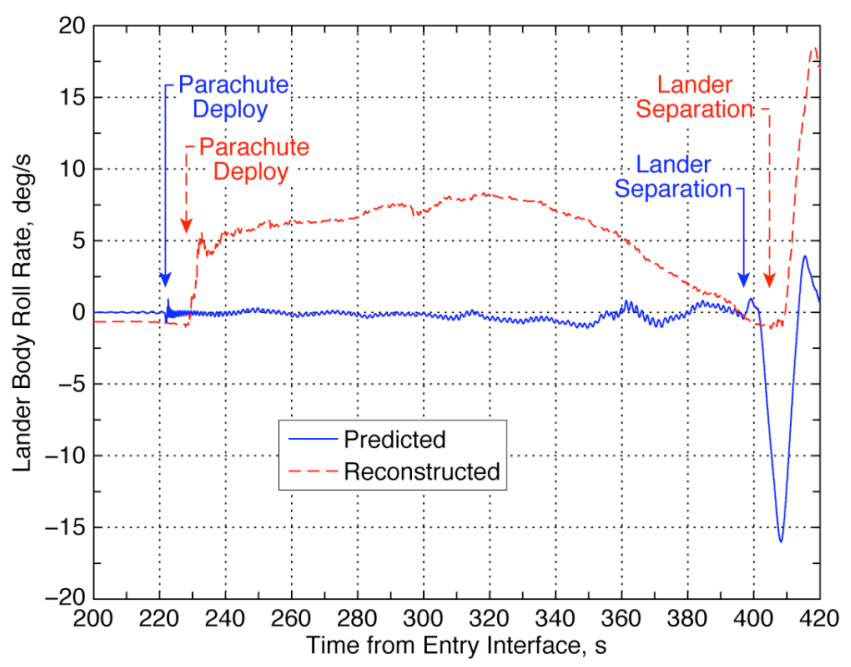

Figure 14. Lander roll rate during the parachute descent phase.

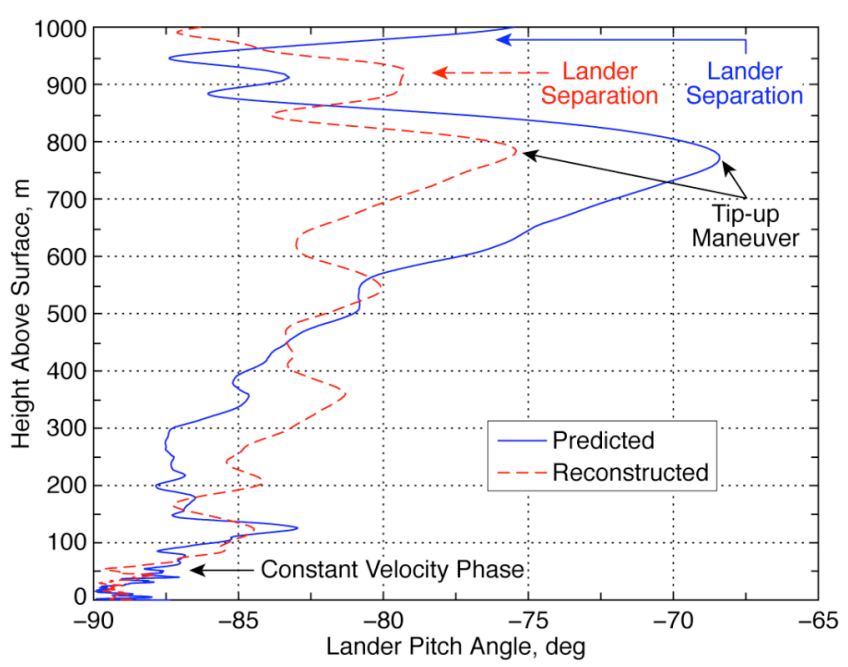

Figure 15. Lander pitch angle during terminal descent. 
the comparison between the two is quite good, where the magnitude, frequency, and phase of the rate oscillations are observed to be very similar. Although, the reconstruction potentially suggests that the environment experienced by Phoenix during its landing was a little more benign than in the prediction. The reconstructed and predicted lander roll rates are compared in Fig. 18. During this phase of descent, the lander is designed to rotate to align its orientation to the proper landing azimuth for solar array pointing. As seen, the magnitude of the roll rate is very similar, although it was in the opposite direction compared to the prediction. This opposite rotation direction is consistent with selecting the shorter rotation arc for the $80^{\circ}$ roll angle change required. Overall, the terminal descent phase went as expected with no anomalies identified.

\section{Preliminary Atmospheric Density Reconstruction}

Three weeks prior to entry, daily weather observations began of the landing site using the Mars Reconnaissance Orbiter (MRO). These observations were made to track movements of potential weather systems over the landing region that could affect the landing. Temperature measurements from the Mars Climate Sounder (MCS) instrument ${ }^{10}$ on MRO were used to make updates to the atmosphere profile used in simulations for calculating the landing location. ${ }^{7}$ Over the course of the three weeks, 14 atmosphere updates were generated utilizing the MCS temperature data. The recommendation of the Atmosphere Team was that the ATM012 profile (using MCS data from May 18) would best represent the landing day atmosphere, since the incremental differences observed in subsequent profiles where within the prediction uncertainty and/or were influenced by transient dust activity. As are result, ATM012 was used to make the final entry parameter update to Phoenix and all landing predictions. ${ }^{7}$

Using the acceleration measurement data from the IMU during entry, a preliminary atmospheric density reconstruction was performed. The atmospheric density was calculated using Eq. (1)

$$
\mathrm{F}=\frac{\rho \mathrm{V}^{2}}{2} \mathrm{C}_{\mathrm{D}} \mathrm{S}=\mathrm{ma}
$$

where $\mathrm{F}$ is force, $\rho$ is atmospheric density, $\mathrm{V}$ is the reconstructed velocity, $C_{D}$ is the capsule drag coefficient, $\mathrm{S}$ is the capsule reference area of $5.5155 \mathrm{~m}^{2}, \mathrm{~m}$ is entry mass of $572.743 \mathrm{~kg}$, and a is the measured acceleration from the IMU. All quantities are known or measured except for the capsule $C_{D}$, which can be obtained from the aerodynamic database ${ }^{6}$ generated for Phoenix. However, the assumption made is that

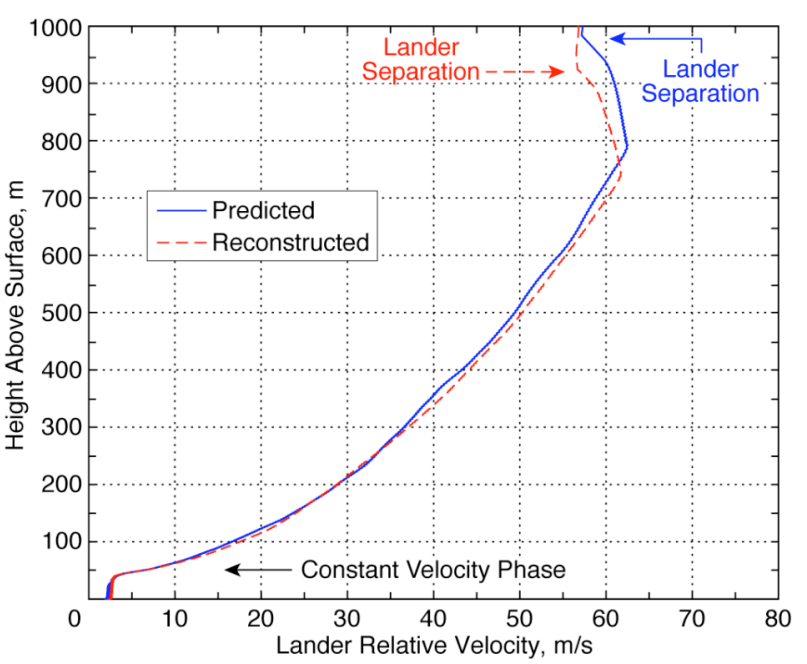

Figure 16. Lander trajectory profile during terminal descent.

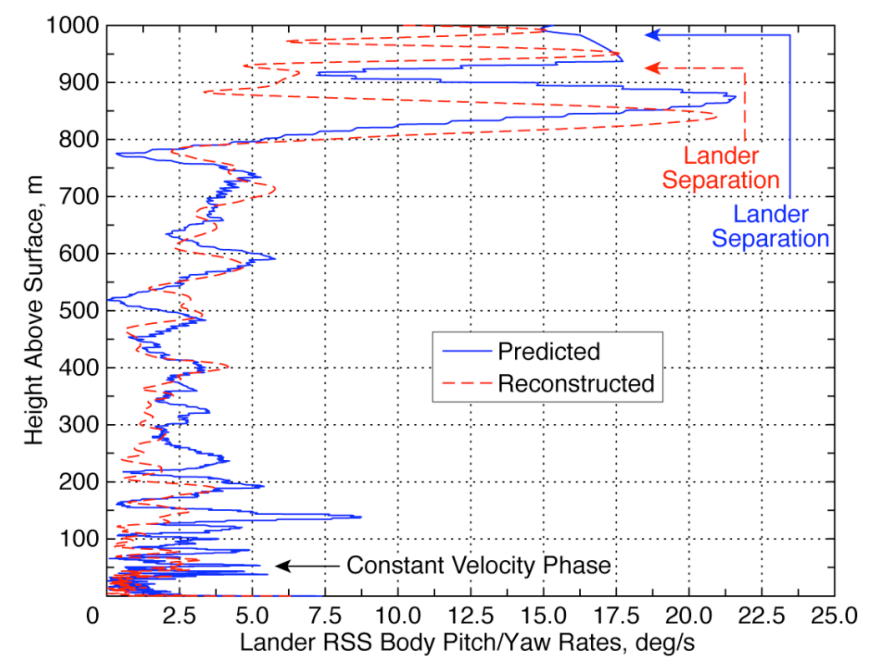

Figure 17. Lander RSS body pitch and yaw rates during terminal descent.

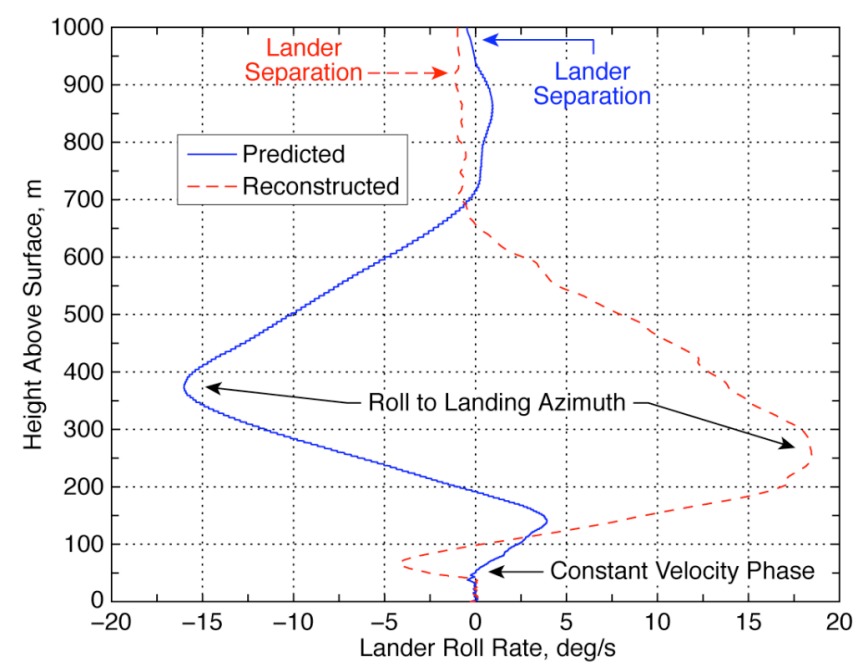

Figure 18. Lander roll rate during terminal descent. 
there is no or only a small error in the $C_{D}$ prediction. In the absence of an onboard air data system to provide direct measurement of dynamic pressure $\left(q=\rho V^{2} / 2\right)$ to separate the density and $C_{D}$ terms in Eq. (1), any errors in the pre-entry predicted value of $C_{D}$ do have a direct impact on the atmospheric density reconstruction. However, historically, the $\mathrm{C}_{\mathrm{D}}$ for blunt bodies during hypersonic flight has been predicted well (within a couple percent), since the aerodynamics are entirely forebody dominated. ${ }^{11}$ The uncertainty in the acceleration measurement (a) must also be considered in evaluating the accuracy of the reconstruction. However, the specific Litton-200 IMU used by Phoenix was very accurate.

Given this assumption, the atmospheric density encountered during the Phoenix entry was reconstructed and is shown in Fig. 17, where it is plotted as a fraction of the ATM012 profile; that is, if the reconstructed density were identical to ATM012, a vertical line at a

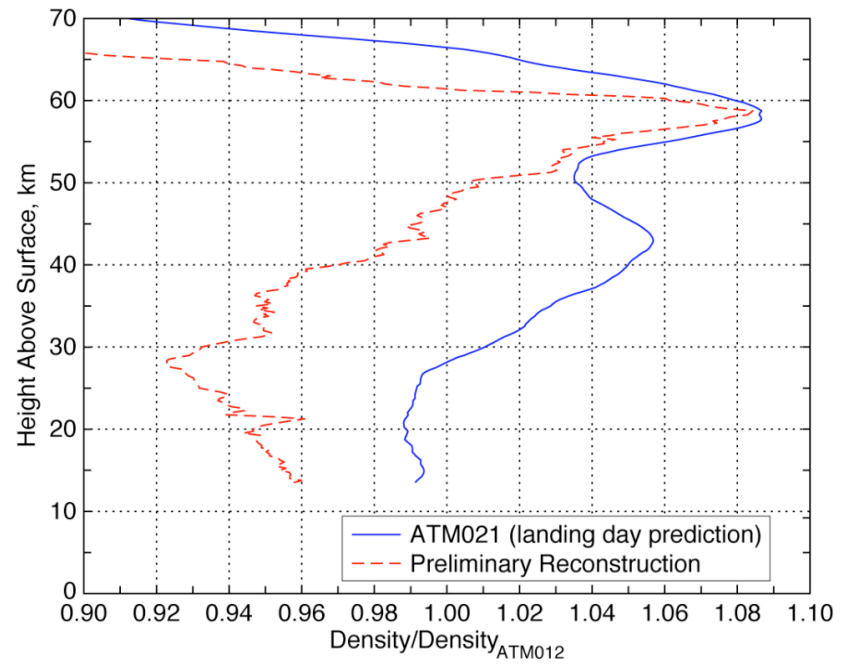

Figure 17. Preliminary atmospheric density reconstruction. value of 1.00 would result. As seen, between approximately $13 \mathrm{~km}$ and $48 \mathrm{~km}$, which is where nearly all of the deceleration occurs, the reconstructed density is less than ATM012 ranging from a few percent lower to a maximum reduction of $8 \%$ at $29 \mathrm{~km}$. This $8 \%$ reduction corresponds to approximately a $1.5-\sigma$ low variation from the atmosphere dispersions generated for Phoenix. ${ }^{12}$ Note, the atmosphere reconstruction stops at parachute deployment (approximately $13 \mathrm{~km}$ ), since the confidence in the parachute $C_{D}$ value is low resulting in an unreliable density estimate.

Also shown in Fig. 17 is ATM021, which was generated after landing using MCS temperature data measured approximately two hours prior to entry on landing day May 25. This temperature data set would produce the best estimate of the landing day atmosphere profile; however, the time required to downlink and process this temperature data precluded its use prior to entry. Between $13 \mathrm{~km}$ to $30 \mathrm{~km}$, ATM021 is similar to ATM012. Above $30 \mathrm{~km}$, ATM021 is denser than ATM012. As such, even if ATM021 was available prior to entry, the reconstructed density would still be less than the best apriori prediction for the landing day atmosphere profile. Shortly after landing, a measurement of the surface pressure and temperature was made and recorded. In future analysis, this preliminary density reconstruction will be refined using this additional data by propagating the density up from the surface.

This lower atmospheric density experienced by Phoenix compared to ATM012 is also consistent with landing further downrange. To ascertain the sensitivity of this lower density on the landing location, it was substituted for ATM012 in the same simulation utilized for predicting the landing day location. The resulting shift in landing location was only $4.2 \mathrm{~km}$ further downtrack. Consequently, this reconstructed lower atmospheric density experienced by Phoenix was not the root cause and was only a small contributor to the landing being $21 \mathrm{~km}$ further downtrack of the prediction (see Section II). As a result, the predominant reason for Phoenix's further downrange landing was due to a larger trim total angle of attack (see Section III) resulting in a lifting trajectory that carried it downtrack.

\section{Reconstruction Performance Overview}

The robustness of the Phoenix entry design was assessed through a Monte Carlo dispersion analysis to statistically determine its performance to off-nominal conditions. References 7, 9, and 13 describe the details of the simulation developed to model the Phoenix EDL phases and the assumptions of the dispersion analysis. In the Monte Carlo dispersion analysis, 2000 random off-nominal cases were simulated varying uncertainties in all the EDL parameters. For example, variations in the initial state vector, capsule mass properties (mass, center of gravity, inertia), initial attitude and attitude rates, hypersonic aerodynamic coefficients, atmospheric density and winds, parachute aerodynamics, descent engine thrust, etc were considered. Results from the final pre-entry prediction using the multi-body simulation ${ }^{9}$ are shown in Table 1, where entry conditions are given at EDL events during the descent in terms of their statistical mean and $99 \%$ high and low variations. These results were the best apriori estimates of the expected entry conditions and their variations.

Also listed in Table 1 for comparison to the pre-entry predictions are trajectory parameters that have been preliminarily reconstructed thus far from the Phoenix flight data. As seen, majority of the reconstructed parameters are close to the mean predictions. For example, the actual parachute deployment dynamic pressure and fuel used during 
the entry and descent were at the mean predicted value. There are, however, a few reconstructed parameters that approach the $99 \%$ high or low variations or even exceed them slightly (e. g., peak deceleration, attitude at peak heat rate). Although, all of the reconstructed parameters are well within the listed EDL design requirements. ${ }^{7}$ Overall, the actual Phoenix entry, descent, and landing was near nominal and close to pre-entry predictions. The reconstruction investigation is ongoing and the results to date are in the process of being refined.

Table 1a: Comparison of Phoenix Pre-Entry Predication and Preliminary Reconstruction Results I

\begin{tabular}{|c|c|c|c|c|c|c|}
\hline Parameter & Units & $\begin{array}{l}99 \% \\
\text { Low }\end{array}$ & Mean & $\begin{array}{l}99 \% \\
\text { High }\end{array}$ & $\begin{array}{c}\text { Design } \\
\text { Requirement }\end{array}$ & $\begin{array}{c}\text { Preliminary } \\
\text { Reconstructed }\end{array}$ \\
\hline \multicolumn{7}{|l|}{ Hypersonic Flight } \\
\hline Peak Heating Rate & $\mathrm{W} / \mathrm{cm}^{2}$ & 44.7 & 46.1 & 47.4 & $<64.0$ & \\
\hline Attitude at Peak Heat Rate & $\operatorname{deg}$ & 0.1 & 0.6 & 1.5 & $<10.0$ & 2.6 \\
\hline Peak Deceleration & Earth G & 8.7 & 9.3 & 9.8 & $<13.0$ & 8.5 \\
\hline Total Heat Load & $\mathrm{J} / \mathrm{cm}^{2}$ & 2305.9 & 2405.8 & 2509.4 & $<3320$ & \\
\hline \multicolumn{7}{|l|}{ Parachute Deployment } \\
\hline Time from Entry & $\mathrm{s}$ & 211.3 & 219.9 & 229.4 & & 227.8 \\
\hline Height (AGL) & $\mathrm{km}$ & 10.0 & 12.7 & 15.7 & & 13.3 \\
\hline Wind-Relative Velocity & $\mathrm{m} / \mathrm{s}$ & 330.9 & 368.3 & 419.1 & & 387.6 \\
\hline Mach Number & & 1.45 & 1.64 & 1.89 & $1.1<\mathrm{M}<2.13$ & 1.7 \\
\hline Dynamic Pressure & $\mathrm{N} / \mathrm{m}^{2}$ & 452.5 & 490.5 & 532.9 & $300<\mathrm{q}<560$ & 488.9 \\
\hline Relative Flight-Path Angle & deg & -33.9 & -28.3 & -22.6 & & -27.1 \\
\hline Relative Azimuth & deg & 106.2 & 111.7 & 116.8 & & 109.8 \\
\hline Total Angle of Attack & deg & 0.2 & 2.3 & 7.3 & $<10.0$ & 4.73 \\
\hline Sensed Acceleration & Earth G & 0.744 & 0.770 & 0.792 & & 0.753 \\
\hline RSS Pitch/Yaw Rates & $\operatorname{deg} / \mathrm{s}$ & 0.4 & 4.5 & 16.1 & & 6.9 \\
\hline Roll Rate & $\operatorname{deg} / \mathrm{s}$ & -1.8 & 0.0 & 1.7 & & -0.83 \\
\hline $\begin{array}{l}\text { Max RSS Pitch/Yaw Rates } \\
\text { thru parachute deployment }\end{array}$ & $\operatorname{deg} / \mathrm{s}$ & 25.3 & 67.9 & 171.1 & & 93.1 \\
\hline \multicolumn{7}{|l|}{ Heatshield Jettison } \\
\hline Height (AGL) & $\mathrm{km}$ & 8.3 & 11.1 & 13.9 & & 11.6 \\
\hline Wind-Relative Velocity & $\mathrm{m} / \mathrm{s}$ & 97.7 & 116.3 & 141.5 & & 123.0 \\
\hline Relative Flight-Path Angle & deg & -52.7 & -44.1 & -32.6 & & -40.5 \\
\hline Dynamic Pressure & $\mathrm{N} / \mathrm{m}^{2}$ & 45.9 & 56.4 & 68.3 & & \\
\hline Mach number & & 0.43 & 0.51 & 0.62 & $<0.8$ & \\
\hline Total Angle of Attack & $\operatorname{deg}$ & 0.7 & 7.9 & 20.8 & & 7.8 \\
\hline Sensed Acceleration & Earth G & 0.73 & 0.83 & 0.95 & & \\
\hline RSS Pitch/Yaw Rates & $\mathrm{deg} / \mathrm{s}$ & 1.3 & 15.5 & 48.3 & $<100.0$ & 16.5 \\
\hline Roll Rate & $\mathrm{deg} / \mathrm{s}$ & -3.8 & -0.1 & 3.4 & & 5.5 \\
\hline
\end{tabular}


Table 1b: Comparison of Phoenix Pre-Entry Predication and Preliminary Reconstruction Results II

\begin{tabular}{|c|c|c|c|c|c|c|}
\hline Parameter & Units & $\begin{array}{l}99 \% \\
\text { Low }\end{array}$ & Mean & $\begin{array}{l}99 \% \\
\text { High }\end{array}$ & $\begin{array}{c}\text { Design } \\
\text { Requirement }\end{array}$ & $\begin{array}{c}\text { Preliminary } \\
\text { Reconstructed }\end{array}$ \\
\hline \multicolumn{7}{|l|}{ Lander Leg Deployment } \\
\hline Height (AGL) & $\mathrm{km}$ & 7.5 & 10.2 & 13.1 & & 10.9 \\
\hline Wind-Relative Velocity & $\mathrm{m} / \mathrm{s}$ & 71.5 & 83.3 & 99.0 & & 91.3 \\
\hline Dynamic Pressure & $\mathrm{N} / \mathrm{m}^{2}$ & 25.8 & 31.1 & 36.8 & & \\
\hline Mach number & & 0.31 & 0.34 & 0.44 & & \\
\hline Total Angle of Attack & deg & 0.7 & 7.9 & 20.8 & & 7.0 \\
\hline RSS Pitch/Yaw Rates & $\mathrm{deg} / \mathrm{s}$ & 1.0 & 12.6 & 40.1 & $<100.0$ & 5.8 \\
\hline Roll Rate & $\mathrm{deg} / \mathrm{s}$ & -3.9 & -0.1 & 19.6 & & 6.4 \\
\hline \multicolumn{7}{|l|}{ Lander Separation } \\
\hline Time from Entry & $\mathrm{s}$ & 348.1 & 392.3 & 435.3 & & 404.9 \\
\hline Time from Parachute Deploy & $\mathrm{s}$ & 134.4 & 172.4 & 211.5 & & 177.1 \\
\hline Height (AGL) & $\mathrm{m}$ & 922.9 & 982.9 & 1249.4 & & 925 \\
\hline Wind-Relative Velocity & $\mathrm{m} / \mathrm{s}$ & 44.3 & 54.3 & 64.4 & & 56.7 \\
\hline Relative Flight-Path Angle & deg & -86.6 & -78.6 & -64.8 & & -75.7 \\
\hline Mach number & & 0.19 & 0.22 & 0.26 & & \\
\hline Total Angle of Attack & deg & 1.9 & 11.9 & 25.0 & & 19 \\
\hline Pitch Angle & deg & -88.5 & -77.5 & -62.5 & & -79.2 \\
\hline RSS Pitch/Yaw Rates & $\mathrm{deg} / \mathrm{s}$ & 1.2 & 11.8 & 32.9 & $<100.0$ & 4.8 \\
\hline Roll Rate & $\mathrm{deg} / \mathrm{s}$ & -5.1 & -0.9 & 3.4 & & -0.97 \\
\hline \multicolumn{7}{|l|}{ Tip-Up } \\
\hline Height & $\mathrm{m}$ & 892.4 & 951.9 & 1213.6 & & 897 \\
\hline \multicolumn{7}{|l|}{ Gravity Turn } \\
\hline Height & $\mathrm{m}$ & 746.9 & 805.8 & 1045.1 & & 720 \\
\hline \multicolumn{7}{|l|}{ Constant Velocity } \\
\hline Height & $\mathrm{m}$ & 45.9 & 51.9 & 57.7 & & 52.1 \\
\hline \multicolumn{7}{|l|}{ Landing } \\
\hline Time from Entry & $\mathrm{s}$ & 392.8 & 436.2 & 479.0 & & 446.1 \\
\hline Time from Parachute Deploy & $\mathrm{s}$ & 177.4 & 216.3 & 254.8 & & 218.3 \\
\hline Time from Lander Separation & $\mathrm{s}$ & 40.5 & 43.9 & 48.7 & & 41.2 \\
\hline Relative Vertical Velocity & $\mathrm{m} / \mathrm{s}$ & 1.4 & 2.1 & 2.7 & $1.0<\mathrm{V}_{\mathrm{v}}<3.4$ & 2.38 \\
\hline Relative Horizontal Velocity & $\mathrm{m} / \mathrm{s}$ & 0.0 & 0.5 & 1.2 & $<1.4$ & 0.06 \\
\hline Fuel Usage During Entry \& Descent & $\mathrm{kg}$ & 35.3 & 37.6 & 41.5 & & 37.6 \\
\hline Landing Footprint size & $\mathrm{km}$ & & & & $110 \times 20$ & $55.1 \times 19.2$ \\
\hline
\end{tabular}

\section{Conclusion}

The Mars Phoenix Lander successfully landed on Mars on May 25, 2008. A reconstruction of Phoenix's entry was performed. The landing was $21 \mathrm{~km}$ further downrange with a northern crosstrack of $5.3 \mathrm{~km}$ than the predicted landing location. Analysis of the flight data revealed that the cause of Phoenix's downtrack and crosstrack landing was a higher trim total angle of attack during the hypersonic phase of the entry, which resulted in Phoenix flying a lifting trajectory. Approximately a $3^{\circ}$ trim total angle of attack was observed compared to a prediction of $0.25^{\circ}$. The cause of this higher trim attitude is not known at this time. Parachute deployment was $6.4 \mathrm{~s}$ later than the pre-entry prediction. This later deployment time was within the variations expected and is consistent with a lifting trajectory. The parachute deployment and inflation process went as expected with no anomalies identified. The peak parachute inflation load was estimated to be $44,800 \mathrm{~N}$, which was well below the $59,600 \mathrm{~N}$ flight load requirement. During the subsequent descent, the oscillations of the lander under the parachute were close to pre-entry predictions. Similarly, the powered terminal descent phase behaved as expect. A preliminary reconstruction of the landing day atmospheric density profile was found to be lower than the a prior prediction, ranging from a few percent less to a maximum of 
$8 \%$. Overall, the preliminary reconstructed entry, descent, and landing trajectory parameters were found to be close to mean pre-entry predictions or within the expected variation. The reconstruction effort is currently ongoing and the results to date are in the process of being refined.

\section{Acknowledgments}

The authors would like to specifically acknowledge the effort of Erik Bailey at the Jet Propulsion Laboratory for processing the Phoenix telemetry data into a form that was usable for this reconstruction investigation. Additionally, the authors would like to recognize the contributions of the entire Phoenix EDL team at the Jet Propulsion Laboratory (Doug Adams, Erik Bailey, Gene Bonfiglio, Jim Chase, Curtis Chen, Ben Cichy, Dan Eldred, Richard Kornfeld, Paul Laufer, Mike Lisano, Rob Manning, Dana Runge, Dara Sabahi, David Skulsky, Cris Windoffer), at Lockheed Martin Space Systems (Tim Gasparrini, Brad Haack, Mark Johnson, Tim Linn, Tim Priser, Jay St. Pierre), and at NASA Langley Research Center (Jody Davis, Artem Dyakonov, Chris Glass, Karl Edquist, Ray Mineck, John Van Norman) for the overall success of the Phoenix landing. A portion of this research was carried out at the Jet Propulsion Laboratory, California Institute of Technology, under a contract with the National Aeronautics and Space Administration. Reference herein to any specific commercial product, process, or service by trade name, trademark, manufacturer, or otherwise, does not constitute or imply its endorsement by the United States Government or the Jet Propulsion Laboratory, California Institute of Technology.

\section{References}

${ }^{1}$ Shotwell, R. "Phoenix - The First Mars Scout Mission (A Midterm Report)," Acta Astronautica 57, July-October 2005, pp. 121-134.

${ }^{2}$ Grover, M. R., Cichy, B. D., and Desai, P. N., "Overview of the Phoenix Entry, Descent, and Landing System Architecture," AIAA Paper 2008-7218, Proceedings of AIAA Guidance, Navigation, and Control Conference, Honolulu, HI, August 2008.

${ }^{3}$ Portock, B. M., Kruizinga, G., Bhat, R., et al., "Navigation Challenges of the Mars Phoenix Lander Mission," AIAA Paper 2008-7214, Proceedings of AIAA Guidance, Navigation, and Control Conference, Honolulu, HI, August 2008.

${ }^{4}$ Ryne, M. S., Graat, E. J., Lau, E., et al., "Orbit Determination for the 2007 Mars Phoenix Lander Mission," AIAA Paper 2008-7215, Proceedings of AIAA Guidance, Navigation, and Control Conference, Honolulu, HI, August 2008.

${ }^{5}$ Dyakonov, A. A., Glass, C. E., Desai, P. N., and Van Norman, J. W., "Aerodynamic Interference Effects Due to Reaction Control System for the Phoenix Entry Capsule," AIAA Paper 2008-7220, Proceedings of AIAA Guidance, Navigation, and Control Conference, Honolulu, HI, August 2008.

${ }^{6}$ Edquist, K. T., Desai, P. N., and Schoenenberger, M., "Aerodynamics Prediction for the Mars Phoenix Entry Capsule," AIAA Paper 2008-7219, Proceedings of AIAA Guidance, Navigation, and Control Conference, Honolulu, HI, August 2008.

${ }^{7}$ Prince, J. L., Desai, P. N., Queen, E. M., Grover, M. R., "Entry, Descent, and Landing Operations Analysis for the Mars Phoenix Lander" AIAA Paper 2008-7349, Proceedings of AIAA Guidance, Navigation, and Control Conference, Honolulu, HI, August 2008.

${ }^{8}$ Bonfiglio, E. L., Spencer, D. A., Arvidson, Stein, T., and Heet, T., "Landing Site Dispersion Analysis and Statistical Assessment for the Mars Phoenix Lander" AIAA Paper 2008-7348, Proceedings of AIAA Guidance, Navigation, and Control Conference, Honolulu, HI, August 2008.

${ }^{9}$ Queen, E. M., Desai, P. N., Prince, J. L, and Cruz. J. R., "Multi-Body Modeling and Simulation for Mars Phoenix Lander Entry, Descent, and Landing," AIAA Paper 2008-7347, Proceedings of AIAA Guidance, Navigation, and Control Conference, Honolulu, HI, August 2008.

${ }^{10}$ McCleese, D. J., Schofield, J. T., Taylor, F. W., Calcutt, S. B., Foote, M. C., Kass, D. M., Leovy, C. B., Paige, D. A., Read, P. L., Zurek, R. W., "Mars Climate Sounder: An investigation of thermal and water vapor structure, dust and condensate distributions in the atmosphere, and energy balance of the polar regions," Journal of Geophysical Research, Vol. 112(E5), DOI: 10.1029/2006JE002790, 2007.

${ }^{11}$ Edquist, K. T., "Computations of Viking Lander Capsule Hypersonic Aerodynamics with Comparisons to Ground and Flight Data," AIAA Paper 2006-6137, AIAA Atmospheric Flight Mechanics Conference and Exhibit, , Keystone, CO, August 2006.

${ }^{12}$ Tamppari, L., J. Barnes, E. Bonfiglio, B. A. Cantor, A. J. Friedson, A. Ghosh, M. R. Grover, D. Kass, T. Z. Martin, M. T. Mellon, T. Michaels, J. R. Murphy, S. Rafkin, M. D. Smith, G. Tsuyuki, D. Tyler, and M. J. Wolff (2008), "The Atmospheric Environment Expected for the Phoenix Landed Season and Location," Journal of Geophysical Research, doi:10.1029/2007JE003034, in press.

${ }^{13}$ Prince, J. L., Desai, P. N., Queen, E. M., Grover, M. R., "Mars Phoenix Entry, Descent, and Landing Simulation Design and Modeling Analysis" AIAA Paper 2008-7507, Proceedings of AIAA Guidance, Navigation, and Control Conference, Honolulu, HI, August 2008. 